\title{
The Second Wave of COVID-19 and Risk of the Third Wave: Factors Affecting the Continuous Transmission, Spread of, and Increased Mortality Associated With Coronavirus Disease 2019 (COVID-19)
}

\author{
Steward Mudenda ${ }^{1 *}$
}

\begin{abstract}
${ }^{1}$ The University of Zambia, School of Health Sciences, Department of Pharmacy, Lusaka, ZAMBIA
\end{abstract} *Corresponding Author: freshsteward@gmail.com

Citation: Mudenda, S. (2021). The Second Wave of COVID-19 and Risk of the Third Wave: Factors Affecting the Continuous Transmission, Spread of, and Increased Mortality Associated With Coronavirus Disease 2019 (COVID-19). European Journal of Environment and Public Health, 5(2), em0081. https://doi.org/10.21601/ejeph/11056

\section{ARTICLE INFO}

Received: 2 Mar. 2021

Accepted: 29 Apr. 2021

\begin{abstract}
The novel coronavirus disease (COVID-19) originated from China and spread globally within a short period. The spread of the first and second wave of COVID-19 were influenced by factors such as population density and weather changes. Areas that are densely populated have reported increased confirmed cases of COVID-19 compared to less populated areas. The main reason for this could be the fact that it is difficult to practice social distancing in overpopulated countries. With regards to temperature changes, most respiratory infections affect people when temperatures are low. This is exaggerated when there is increased air pollution in the environment. Economic factors have prevented countries to conduct a lockdown of epicentre towns and cities. This is in fear of an economic shut down because some cities are economic cornerstones of countries. Politically, most political leaders have failed to lockdown their countries for the fear of losing political support from their citizens. Further, some traditional and religious beliefs have also influenced the spread of COVID-19, thereby leading to increased morbidity and mortality globally. The spread of COVID-19 has been worsened by peoples negative perceptions and misinformation that COVID-19 is a myth, and thus relax to adhere to the recommended preventive measures. Besides, comorbidities, poor health-seeking behavior, and lack of vaccines, inadequate treatment modalities and test kits have worsened the failure to contain the COVID-19 pandemic. The initiation and implementation of COVID-19 vaccination programs will help reduce the disease burden. However, there is need to improve the awareness and uptake of COVID-19 vaccines globally. Low COVID-19 vaccine acceptability and uptake due vaccine hesitancy have been reported globally. Hence, there is a need for continuous community sensitisation and education programmes and campaigns on the benefits of vaccines in containing disease outbreaks.
\end{abstract}

Keywords: second wave, third wave, factors, spread, transmission, coronavirus disease, COVID-19, mortality, COVID-19 vaccines, vaccine acceptability, vaccine hesitancy

\section{INTRODUCTION}

The novel coronavirus disease 2019 (COVID-19) was first reported in December 2019 (Liu et al., 2020). The first cases are believed to have originated from the Wuhan City of China (Andersen et al., 2020; Banda, Neene, and Mudenda, 2020; Kasanga et al., 2020; Mudenda et al., 2020a; Ullah et al., 2021). COVID-19 is caused by severe acute respiratory syndrome coronavirus 2 (SARS-CoV-2) that is usually transmitted through inhalation of the virus (Mudenda et al., 2021; Shrestha et al., 2020). Patients present with a dry cough, headache, fever, diarrhea, fatigue, difficulty in breathing, and chest pain (Huang et al., 2020; Mudenda, 2020; Phiri et al., 2020).
Being a respiratory tract infection, COVID-19 airborne transmission is the major route of the spread of SAR-CoV-2 among different populations more especially in crowded environments (Zhang et al., 2020). However, provided that people abide by the preventive measures against COVID-19, the spread is likely to decline (Lahiri et al., 2020). Researchers warned of the possibility of the second wave of COVID-19, towards the end of the year 2020, the second wave of COVID19 hit many countries (Cacciapaglia et al., 2020; Cousins, 2020; Looi, 2020; Tayech et al., 2020; Vaid et al., 2020; Xu and Li, 2020). This could have occurred due to several factors.

In this paper, some factors that influence the spread of COVID-19 have been discussed. Nevertheless, the factors that influence the spread of COVID-19 are not limited to the ones discussed in this paper. 


\section{ECONOMIC, POLITICAL, SOCIAL AND RELIGIOUS FACTORS AND MISINFORMATION ABOUT COVID-19}

Many countries, especially developing countries, cannot afford to go into complete lockdown due to fear of an economic meltdown. Many people depend on their daily earnings to survive in meeting their day-to-day needs (Yezli and Khan, 2020). Hence, practices such as social distancing may be difficult to implement as certain jobs or businesses require people to interact with others and be in crowded places (Yoosefi Lebni et al., 2020). Therefore, a total lockdown can mean that most people will have no jobs, no food, and no money to buy what they need, hence, adding a burden to already increased unemployment levels in low-income countries. Political leaders play important roles in curbing the transmission and spread of COVID-19 (Memish et al., 2020). However, political leaders may lead to the escalation of COVID-19 cases and deaths if they ignore science, set priorities other than curbing COVID-19, ignore preventive measures such as wearing of face masks and social distancing and ignoring transparent coordination of public health efforts in the fight against COVID-19 (Yezli and Khan, 2020). Political leaders must ensure they observe the COVID-19 preventive measures such as masking up at all times, reduction in group sizes to a maximum of 50 people, hand sanitizing, adequate handwashing, and social distancing.

In some areas, people lack materials such as antiseptics for using in the prevention of COVID-19 (Yoosefi Lebni et al., 2020). This may eventually lead to individuals contracting COVID-19 and damage to their respiratory tract, thereby increasing mortality rates associated with COVID-19. The continued religious gatherings in some countries are another factor fostering the transmission and spread of SARS-CoV-2 (Yezli and Khan, 2020). Besides, due to traditional and religious beliefs, some people still think COVID-19 is a myth and does not exist (Yezli and Khan, 2020). The negative perceptions about COVID-19 have continued being among the major factors leading to the escalation of COVID-19 infections. Therefore, measures must be taken into consideration to address all factors that are contributing to the continuous transmission and spread of SARS-CoV-2.

There has been a lot of misinformation about COVID-19, especially via social media like Facebook (Obiala et al., 2020). Inaccurate information is shared more easily and quickly than accurate one (CDC, 2020). Misinformation about the effectiveness of adhering to COVID-19 preventive measures negatively affects the containment of the pandemic (Obiala et al., 2020; van der Linden, Roozenbeek, and Compton, 2020). There is strong evidence that the recommended COVID-19 preventive measures (social and physical distancing, wearing of face masks and adequate washing of hands) reduce the risk of being infected (Chu et al., 2020; Obiala et al., 2020; Qian and Jiang, 2020). Conspiracy theories about COVID-19 and vaccines continue to be a global problem (Freeman et al., 2020). These conspiracy theories can reduce peoples' perceptions about the risk of being infected and increase their resistance to be vaccinated against COVID-19 (Duplaga, 2020; Freeman et al., 2020). Therefore, health authorities must ensure that they monitor and address all the misinformation regarding COVID-19 prevention, treatment and vaccinations.

\section{CHANGE IN WEATHER PATTERNS}

Despite a weak relationship between weather change and COVID-19 transmission, a temperature change has been reported to be among the reasons that affect the spread of COVID-19. Some studies have shown that there is a relationship between a decrease in temperature and an increase in the number of confirmed cases of COVID-19 (Le et al., 2020; Wang et al., 2020; Xie and Zhu, 2020). However, a study in Brazil reported that high temperatures did not reduce the number of COVID-19 confirmed cases (Núñez-Delgado, 2020). Other studies have reported that every $1^{\circ} \mathrm{C}$ increase in temperature leads to a decline in daily reported confirmed COVID-19 cases (Prata et al., 2020; Wu et al., 2020). This shows that warm weather leads to a decline in confirmed COVID-19 cases while cold weather leads to an increase in daily reported COVID-19 cases. Unfortunately, there is no confirmed evidence supporting that warm weather leads to a decline in the number of COVID-19 confirmed cases (Xie and Zhu, 2020). As a result of climate change, changes in weather patterns have influenced air pollution and thus the spread of respiratory tract infections (Borge et al., 2019).

\section{POPULATION DENSITY}

COVID-19 has been reported to spread faster in highdensity populations (Roy and Ghosh, 2020). Population density plays a vital role in the spread of COVID-19 in that it increases air pollution (Liu et al., 2020). Therefore, if a geographical area is overpopulated, the chances of continuous spread of COVID-19 are very high. Overpopulation has been reported to make it difficult for people to practice social distancing (Wilkinson et al., 2020). Studies have reported a positive correlation between population density and the number of COVID-19 confirmed cases. In Iran (Ahmadi et al., 2020) and Turkey (Şahin, 2020), it was confirmed that areas that were highly populated reported higher cases of COVID-19 than less populated areas.

Highly populated rooms with less ventilation also influence the transmission and spread of COVID-19 (Tantrakarnapa et al., 2020). It is evident that even in crowded sports events, the transmission of COVID-19 is very high (Cao et al., 2021). Therefore, to reduce the transmission and spread of COVID-19, social gatherings and crowds must be minimized.

\section{PREMATURE RELAXATION OF INTERVENTIONS}

During the peak of the first wave of COVID-19, the majority of people adhered to preventive measures. Unfortunately, towards the end of the year 2020, most people relaxed and never paid attention to the COVID-19 preventive measures (Leung et al., 2020; Tayech et al., 2020). Governments (policy 
interventions) also relaxed and never enforced public health preventive measures (Vaid et al., 2020). As a result, the second wave of COVID-19 was reported in different countries and it claimed a lot of lives. Relaxation in adhering to the recommended COVID-19 guidelines has put the globe at risk of the third wave of the pandemic.

\section{FACTORS INFLUENCING INCREASED MORTALITY RATE ASSOCIATED WITH AND DUE TO COVID-19}

Studies have reported that mortality due to and associated with COVID-19 has been worsened by the existence of concurrent or chronic infections in COVID-19 positive patients. Among the commonest conditions that lead to increased mortality among COVID-19 patients include myocardial infarction, chronic pulmonary disease, renal disease, congested heart disease, liver disease, dementia, and metastatic solid tumors (Harrison et al., 2020). The death rate is high in elderly patients because of the history and comorbidities such as diabetes, cardiovascular and lung disease (Zhou et al., 2020). Other comorbidities leading to increased mortality rates among COVID-19 patients include hepatitis B and human immunodeficiency virus (HIV), other respiratory illnesses, renal disease, and immunodeficiencies (Paudel, 2020). Poor health-seeking behavior also increases mortality and thus many deaths have been reported as brought-in dead (Chileshe et al., 2020). People choose to selfmedicate while their condition worsens (Mudenda et al., 2020b). This may lead to exacerbation of COVID-19 infections and mortality.

Lack of vaccines and no proven treatment modalities have led to failure to contain the COVID-19 pandemic (Jean et al., 2020; Vijayvargiya et al., 2020). The good news is that, many pharmaceutical companies are now developing vaccines for use against COVID-19. The vaccines will protect people against the deadly virus, SARS-CoV-2 (Li et al., 2020; Randolph and Barreiro, 2020). However, access to quality, safe and effective COVID-19 vaccines remain a global challenge (Wouters et al., 2021). Besides, the low acceptability and uptake of the COVID-19 vaccines in some countries poses a danger in the fight against COVID-19 (Barello et al., 2020; Sallam et al., 2021). Vaccine hesitancy remains a global challenge and may affect the goal of reaching community herd immunity (Kanyike et al., 2021; Skjefte et al., 2021). In resource-constrained countries, a lack of COVID-19 testing kits and accuracy has been reported (Giri and Rana, 2020; Vandenberg et al., 2020). This may affect the diagnosis of COVID-19 and thus delay treatment or interventions.

\section{CONCLUSION}

The second wave of COVID-19 has led to increased morbidity and mortality rates more especially in the developing countries. There is a risk of experiencing a third wave of COVID-19 in many countries due to many factors. Factors such as weather patterns, politics, economics, population density, and comorbidities have led to the continuous transmission and spread of the SARS-CoV-2. Lack of vaccines, treatment modalities and COVID-19 test kits are among contributing factors to the worsening and continuous transmission, spread and increased morbidity rates associated with COVID-19. There is a need to promote the awareness of COVID-19 vaccination programs globally in order to increase the acceptability and uptake of the vaccines. Therefore, containment of the COVID-19 pandemic requires a multisectoral approach. Strategies that address vaccine hesitancy must be developed so that the majority of people are vaccinated and herd immunity reached.

Funding: No funding was received for this article.

Acknowledgements: The author is grateful to the University of Zambia e-Library for providing access to the majority of the articles that were used in this publication. The author also extends sincere thanks to Ms. Emmah Charity Nhoma, from the University of Zambia, for proofreading and editing the article.

Declaration of interest: The author declares no competing interest.

Ethics approval and consent to participate: Not applicable.

Availability of data and materials: All data generated or analyzed during this study are available for sharing when appropriate request is directed to the author.

\section{REFERENCES}

Ahmadi, M., Sharifi, A., Dorosti, S., Jafarzadeh Ghoushchi, S. and Ghanbari, N. (2020). Investigation of effective climatology parameters on COVID-19 outbreak in Iran. Science of the Total Environment, 729, 138705. https://doi.org/10.1016/j.scitotenv.2020.138705

Andersen, K. G., Rambaut, A., Lipkin, W. I., Holmes, E. C. and Garry, R. F. (2020). The proximal origin of SARS-CoV-2. Nature Medicine, 26, 450-452. https://doi.org/10.1038/ s41591-020-0820-9

Banda, M., Neene, V. and Mudenda, S. (2020). Community pharmacists' role as antibiotic stewards in the fight against coronavirus disease 2019. World Journal of Advanced Research and Reviews, 2020(01), 2581-9615. https://doi.org/ 10.30574/wjarr

Barello, S., Nania, T., Dellafiore, F., Graffigna, G. and Caruso, R. (2020). "Vaccine hesitancy" among university students in Italy during the COVID-19 pandemic. European Journal of Epidemiology, 35(8), 781-783. https://doi.org/10.1007/ s10654-020-00670-z

Borge, R., Requia, W. J., Yagüe, C., Jhun, I. and Koutrakis, P. (2019). Impact of weather changes on air quality and related mortality in Spain over a 25 year period [19932017]. Environment International, 133, 105272. https://doi.org/10.1016/j.envint.2019.105272

Cacciapaglia, G., Cot, C. and Sannino, F. (2020). Second wave COVID-19 pandemics in Europe: a temporal playbook. Scientific Reports, 10(1), 1-8. https://doi.org/10.1038/ s41598-020-72611-5

Cao, W., Chen, C., Li, M., Nie, R., Lu, Q., Song, D., Li, S., Yang, T., Liu, Y., Du, B. and Wang, X. (2021). Important factors affecting COVID-19 transmission and fatality in metropolises. Public Health, 190, e21-e23. https://doi.org/ 10.1016/j.puhe.2020.11.008 
CDC, Coronavirus (COVID-19). 2020. Available at: https://www.cdc.gov/coronavirus/2019-ncov/index.html (Accessed: 10 June 2021).

Chileshe, M., Mulenga, D., Mfune, R. L., Nyirenda, T. H., Mwanza, J., Mukanga, B., Mudenda, S. and Daka, V. (2020). Increased number of brought-in-dead cases with COVID19: is it due to poor health-seeking behaviour among the Zambian population? Pan African Medical Journal, 37, 136. https://doi.org/10.11604/pamj.2020.37.136.25967

Chu, D. K., Akl, E. A., Duda, S., Solo, K., Yaacoub, S., Schünemann, H. J., et al. (2020). Physical distancing, face masks, and eye protection to prevent person-to-person transmission of SARS-CoV-2 and COVID-19: a systematic review and meta-analysis. The Lancet, 395(10242), 19731987. https://doi.org/10.1016/S0140-6736(20)31142-9

Cousins, S. (2020). Afghanistan braced for second wave of COVID-19. Lancet, 396(10264), 1716-1717. https://doi.org/10.1016/S0140-6736(20)32529-0

Duplaga, M. (2020). The determinants of conspiracy beliefs related to the COVID-19 pandemic in a nationally representative sample of Internet users. International journal of environmental research and public health, 17(21), 7818. https://doi.org/10.3390/ijerph17217818

Freeman, D., Waite, F., Rosebrock, L., Petit, A., Causier, C., East, A., et al. (2020). Coronavirus conspiracy beliefs, mistrust, and compliance with government guidelines in England. Psychological Medicine, 1-13. https://doi.org/10.1017/S0033291720001890

Giri, A. K. and Rana, D. R. (2020). Charting the challenges behind the testing of COVID-19 in developing countries: Nepal as a case study. Biosafety and Health, 2(2), 53-56. https://doi.org/10.1016/j.bsheal.2020.05.002

Harrison, S. L., Fazio-Eynullayeva, E., Lane, D. A., Underhill, P. and Lip, G. Y. H. (2020). Comorbidities associated with mortality in 31,461 adults with COVID-19 in the United States: A federated electronic medical record analysis. PLOS Medicine, 17(9), e1003321. https://doi.org/10.1371/ journal.pmed.1003321

Huang, C., Wang, Y., Li, X., Ren, L., Zhao, J., et al. (2020). Clinical features of patients infected with 2019 novel coronavirus in Wuhan, China. The Lancet, 395(10223), 497506. https://doi.org/10.1016/S0140-6736(20)30183-5

Jean, S. S., Lee, P. I. and Hsueh, P. R. (2020). Treatment options for COVID-19: The reality and challenges. Journal of Microbiology, Immunology and Infection, 53(3), 436-443. https://doi.org/10.1016/j.jmii.2020.03.034

Kanyike, A. M., Olum, R., Kajjimu, J., Ojilong, D., Akech, G. M, Nassozi, D. R., et al. (2021). Acceptance of the coronavirus disease-2019 vaccine among medical students in Uganda, Tropical Medicine and Health, 49(1), 111. https://doi.org/10.1186/s41182-021-00331-1

Kasanga, M., Mudenda, S., Gondwe, T., Chileshe, M., Solochi, B. and $\mathrm{Wu}, \mathrm{J}$. (2020). Impact of COVID-19 on blood donation and transfusion services at Lusaka provincial blood transfusion centre, Zambia. Pan African Medical Journal, 35(2), 74. https://doi.org/10.11604/pamj.supp. 2020.35.2.23975
Lahiri, A., Jha, S. S., Bhattacharya, S., Ray, S. and Chakraborty, A. (2020). Effectiveness of preventive measures against COVID-19: A systematic review of In Silico modeling studies in indian context. Indian Journal of Public Health, 64(Supplement), S156-S167. https://doi.org/10.4103/ijph. IJPH_464_20

Le, N., Le, A., Parikh, J., Brooks, J., Gardellini, T. and Izurieta, R. (2020). Ecological and health infrastructure factors affecting the transmission and mortality of COVID-19. https://doi.org/10.21203/rs.3.rs-19504/v1

Leung, K., Wu, J. T., Liu, D. and Leung, G. M. (2020). First-wave COVID-19 transmissibility and severity in China outside Hubei after control measures, and second-wave scenario planning: a modelling impact assessment. The Lancet, 395(10233), 1382-1393. https://doi.org/10.1016/S01406736(20)30746-7

Li, Y. Der, Chi, W. Y., Su, J. H., Ferrall, L., Hung, C. F. and Wu, T. C. (2020). Coronavirus vaccine development: from SARS and MERS to COVID-19. Journal of Biomedical Science. BioMed Central Ltd, p. 104. https://doi.org/10.1186/ s12929-020-00695-2

Liu, J., Zhou, J., Yao, J., Zhang, X., Li, L., et al. (2020). Impact of meteorological factors on the COVID-19 transmission: A multi-city study in China. Science of the Total Environment, 726, 138513. https://doi.org/10.1016/ j.scitotenv.2020.138513

Liu, Y. C., Kuo, R. L. and Shih, S. R. (2020). COVID-19: The first documented coronavirus pandemic in history. Biomedical Journal, 43(4), 328-333. https://doi.org/10.1016/ j.bj.2020.04.007

Looi, M. K. (2020). Covid-19: Is a second wave hitting Europe? The BMJ, 371, m4113. https://doi.org/10.1136/bmj.m4113

Memish, Z. A., Ebrahim, S. H., Kattan, R. F., Alharthy, A., Alqahtani, S. A. and Karakitsos, D. (2020). Leadership to prevent COVID-19: is it the most important mitigation factor? Travel Medicine and Infectious Disease, 38, 101925. https://doi.org/10.1016/j.tmaid.2020.101925

Mudenda, S., Mukosha, M., Mwila, C., Saleem, Z., Kalungia, A. C., Munkombwe, D., et al. (2021). Impact of the coronavirus disease on the mental health and physical activity of pharmacy students at the University of Zambia: a crosssectional study. International Journal of Basic \& Clinical Pharmacology, 10(4), 324-332. https://doi.org/10.18203/ 2319-2003.ijbcp20211010

Mudenda, S. (2020). Letter to Editor: Coronavirus Disease (COVID-19): A Global Health Problem. International Journal of Pharmaceutics \& Pharmacology, 4(1), 1-2. https://doi.org/10.31531/2581-3080.1000141

Mudenda, S., Zulu, A., Phiri, M. N., Ngazimbi, M., Mufwambi, W., Kasanga, M. and Banda, M. (2020a). Impact of coronavirus disease 2019 (COVID-19) on college and university students: A global health and education problem. Aquademia, 4(2), ep20026. https://doi.org/ 10.29333/aquademia/8494 
Mudenda, S., Witika, B. A., Sadiq, M. J., Banda, M., Mfune, R. L., Daka, V., Kalui, D., Phiri, M. N., Kasanga, M., Mudenda, F. and Mufwambi, W. (2020b). Self-medication and its Consequences during \& after the Coronavirus Disease 2019 (COVID-19) Pandemic: A global health problem. European Journal of Environment and Public Health, 5(1), em0066. https://doi.org/10.29333/ejeph/9308

Núñez-Delgado, A. (2020). What do we know about the SARSCoV-2 coronavirus in the environment? Science of the Total Environment, 727, 138647. https://doi.org/10.1016/ j.scitotenv.2020.138647

Obiała, J., Obiała, K., Mańczak, M., Owoc, J. and Olszewski, R. (2021). COVID-19 misinformation: Accuracy of articles about coronavirus prevention mostly shared on social media. Health policy and technology, 10(1), 182186. https://doi.org/10.1016/j.hlpt.2020.10.007

Paudel, S. S. (2020). A meta-analysis of 2019 novel corona virus patient clinical characteristics and comorbidities. Research Square. https://doi.org/10.21203/rs.3.rs-21831/v1

Phiri, M. N., et al. (2020). Coronavirus disease 2019 (COVID19): The role of pharmacists in the fight against COVID-19 pandemic. International Journal of Pharmaceutics \& Pharmacology, 4(1), 1-3. https://doi.org/10.31531/25813080.1000143

Prata, D. N., Rodrigues, W. and Bermejo, P. H. (2020). Temperature significantly changes COVID-19 transmission in (sub)tropical cities of Brazil. Science of the Total Environment, 729, 138862. https://doi.org/10.1016/ j.scitotenv.2020.138862

Qian, M., \& Jiang, J. (2020). COVID-19 and social distancing. Zeitschrift fur Gesundheitswissenschaften - Journal of public health, 13. Advance online publication. https://doi.org/10.1007/s10389-020-01321-z

Randolph, H. E. and Barreiro, L. B. (2020). Herd Immunity: Understanding COVID-19. Immunity. Cell Press, pp. 737741. https://doi.org/10.1016/j.immuni.2020.04.012

Roy, S. and Ghosh, P. (2020). Factors affecting COVID-19 infected and death rates inform lockdown-related policymaking. PLOS ONE, 15(10), e0241165. https://doi.org/10.1371/journal.pone.0241165

Şahin, M. (2020). Impact of weather on COVID-19 pandemic in Turkey. Science of the Total Environment, 728, 138810. https://doi.org/10.1016/j.scitotenv.2020.138810

Sallam, M., Dababseh, D., Eid, H., Hasan, H., Taim, D., et al. (2021). Low COVID-19 vaccine acceptance is correlated with conspiracy beliefs among university students in Jordan. International Journal of Environmental Research and Public Health, 18(5), 2407. https://doi.org/10.3390/ ijerph18052407

Shrestha, S., Jha, N., Palaian, S. and Shankar, P. R. (2020). Knowledge, awareness and preparedness regarding coronavirus disease 2019 pandemic among community pharmacy practitioners working in Kathmandu, Nepal: A pilot study. SAGE Open Medicine, 8, 205031212097451. https://doi.org/10.1177/2050312120974513
Skjefte, M., Ngirbabul, M., Akeju, O., Escudero, D., HernandezDiaz, S., Wyszynski, D. F. and Wu, J. W. (2021). COVID-19 vaccine acceptance among pregnant women and mothers of young children: results of a survey in 16 countries. European Journal of Epidemiology, 36(2), 197211. https://doi.org/10.1007/s10654-021-00728-6

Tantrakarnapa, K., Bhopdhornangkul, B. and Nakhaapakorn, K. (2020). Influencing factors of COVID-19 spreading: a case study of Thailand. Journal of Public Health (Germany), 1-7. https://doi.org/10.1007/s10389-020-01329-5

Tayech, A., Mejri, M. A., Makhlouf, I., Mathlouthi, A., Behm, D. G. and Chaouachi, A. (2020). Second wave of COVID-19 global pandemic and athletes' confinement: Recommendations to better manage and optimize the modified lifestyle. International Journal of Environmental Research and Public Health, 17(22), 8385. https://doi.org/10.3390/ijerph17228385

Ullah, M., Wahab, A., Saeed, S., Khan, S. U., Ali, H., et al. (2021). Coronavirus and its terrifying inning around the globe: The pharmaceutical cares at the main frontline. Chemosphere, 275, 129968. https://doi.org/10.1016/ j.chemosphere.2021.129968

Vaid, S., McAdie, A., Kremer, R., Khanduja, V. and Bhandari, M. (2020). Risk of a second wave of Covid-19 infections: using artificial intelligence to investigate stringency of physical distancing policies in North America. International Orthopaedics, 44(8), 1581-1589. https://doi.org/10.1007/ s00264-020-04653-3

van der Linden, S., Roozenbeek, J. and Compton, J. (2020). Inoculating against fake news about COVID-19. Frontiers in psychology, 11, 566790. https://doi.org/10.3389/fpsyg.2020. 566790

Vandenberg, O., Martiny, D., Rochas, O., van Belkum, A. and Kozlakidis, Z. (2020). Considerations for diagnostic COVID-19 tests. Nature Reviews Microbiology, 19, 171-183. https://doi.org/10.1038/s41579-020-00461-z

Vijayvargiya, P., Esquer Garrigos, Z., Castillo Almeida, N. E., Gurram, P. R., Stevens, R. W. and Razonable, R. R. (2020). Treatment considerations for COVID-19: A critical review of the evidence (or lack thereof). Mayo Clinic Proceedings, 95(7), 1454-1466. https://doi.org/10.1016/j.mayocp.2020. 04.027

Wang, M., Jiang, A., Gong, L., Lu, L., Guo, W., et al. (2020). Temperature significant change COVID-19 Transmission in 429 cities. medRxiv, 2020.02.22.20025791. https://doi.org/10.1101/2020.02.22.20025791

Wilkinson, A., Ali, H., Bedford, J., Boonyabancha, S., Connolly, C., et al. (2020). Local response in health emergencies: key considerations for addressing the COVID-19 pandemic in informal urban settlements. Environment and Urbanization, 32(2), 503-522. https://doi.org/10.1177/0956247820922843

Wouters, O. J., Shadlen, K. C., Salcher-Konrad, M., Pollard, A. J., Larson, H. J., Teerawattananon, Y. and Jit, M. (2021). Challenges in ensuring global access to COVID-19 vaccines: production, affordability, allocation, and deployment. The Lancet, 397(10278), 1023-1034. https://doi.org/10.1016/s0140-6736(21)00306-8 
Wu, Y., Jing, W., Liu, J., Ma, Q., Yuan, J., Wang, Y., Du, M. and Liu, M. (2020). Effects of temperature and humidity on the daily new cases and new deaths of COVID-19 in 166 countries. Science of the Total Environment, 729, 139051. https://doi.org/10.1016/j.scitotenv.2020.139051

Xie, J. and Zhu, Y. (2020). Association between ambient temperature and COVID-19 infection in 122 cities from China. Science of the Total Environment, 724, 138201. https://doi.org/10.1016/j.scitotenv.2020.138201

$\mathrm{Xu}, \mathrm{S}$. and Li, Y. (2020). Beware of the second wave of COVID19. The Lancet, 395(102233), 1321-1322. https://doi.org/ 10.1016/S0140-6736(20)30845-X

Yezli, S. and Khan, A. (2020). COVID-19 social distancing in the Kingdom of Saudi Arabia: Bold measures in the face of political, economic, social and religious challenges. Travel Medicine and Infectious Disease, 37, 101692. https://doi.org/10.1016/j.tmaid.2020.101692
Yoosefi Lebni, J., Abbas, J., Moradi, F., Salahshoor, M. R., Chaboksavar, F., Irandoost, S. F., Nezhaddadgar, N. and Ziapour, A. (2020). How the COVID-19 pandemic effected economic, social, political, and cultural factors: A lesson from Iran. International Journal of Social Psychiatry, 67(3), 002076402093998.

https://doi.org/10.1177/0020764020939984

Zhang, R., Li, Y., Zhang, A. L., Wang, Y. and Molina, M. J. (2020). Identifying airborne transmission as the dominant route for the spread of COVID-19', Proceedings of the National Academy of Sciences of the United States of America, 117(26), 14857-14863. https://doi.org/10.1073/pnas.2009 637117

Zhou, F., Yu, T., Du, R., Fan, G., Liu, Y., et al. (2020). Clinical course and risk factors for mortality of adult inpatients with COVID-19 in Wuhan, China: a retrospective cohort study. The Lancet, 395(10229), 1054-1062. https://doi.org/10.1016/S0140-6736(20)30566-3 